The list of near patient tests that are potentially relevant to making urgent clinical decisions is substantial: tests for antibodies to Helicobacter pylori, ${ }^{7} \mathrm{C}$ reactive protein, ${ }^{8}$ and cardiac troponin $\mathrm{T}^{910}$ are already available, and many testssuch as for glycated proteins and for numerous drugs-are under development. An immediate result from a near patient test for $\mathrm{C}$ reactive protein might enable a doctor to avoid unnecessary prescribing of an antibiotic (by distinguishing between viral and bacterial infection) or help in the differential diagnosis of acute abdominal pain. ${ }^{11}$ Near patient testing may also encourage doctors to be more discriminating in their choice of investigations, since the trend is towards developing devices that perform single rather than multiple tests.

In monitoring disease, near patient testing promises greater convenience to patients, ${ }^{12}$ improved therapeutic control (if results are presented during the consultation), ${ }^{13}$ and reduced overall health costs. ${ }^{14}$ However, the full potential of near patient testing can be exploited only by finding the clinical niches where its use would be most likely to influence practice beneficially ${ }^{14}$ and then finding mechanisms to enable its wider dissemination. This would go beyond the regular problems of implementing research findings, since for most general practices in Britain no method exists for funding such diagnostic testing.

No discussion on near patient testing can omit the importance of external quality assurance. ${ }^{15}$ This priority might be best met by a coherent policy to develop near patient testing in primary care in collaboration with hospital clinical chemists. Equipment provided by specialists and used by general practice staff who have undergone laboratory training, combined with external quality assurance from central laboratories, might prove the most durable model.
In many situations primary care physicians will continue to use the powerful diagnostic tool of waiting and seeing. ${ }^{16}$ However, the incremental use of fully evaluated near patient testing could help primary care to take its next logical evolutionary leap, to subsume the remaining functions of the hospital general physician within community settings.

RICHARD HOBBS

Department of General Practice,

Professor of general practice

The Medical School,

University of Birmingham,

Birmingham B15 2TT

1 Woolf S, Kamerowdb $\mathrm{H}$. Testing for uncommon conditions. The heroic search for positive test results. Arch Intern Med 1990;150:2451-8.

2 Hilton S. Near patient testing in general practice: a review. Br f Gen Pract 1990;40:32-6.

3 Fischer PM. Laboratory testing in the 1990s. F Fam Pract 1991;33:453-4.

4 DeNeef $P$. The expanding role of the office laboratory. $\mathcal{F}$ Fam Pract 1986;22:215-6.

5 Hiortdahl P. The silent revolution. Scand f Prim Health Care 1990;8:188-90.

6 Fitzmaurice DA, Hobbs FDR, Murray E. Anticoagulation in patients with atrial fibrillationexpert software may be the answer. BMF 1994;308:415-6.

7 Delaney BC, Kenkre JE, Hobbs FDR. A whole blood near patient test for antibodies to Helicobacter pylori: effect on the management of dyspepsia in primary care. Fam Pract 1995;2:263-4.

8 Kenkre JE, Hobbs FDR, Carter YH, Thorpe GH. Evaluation of a C-reactive protein assay (NycoCard) as a near patient test in primary care. Clin Rheumatol 1994;13:359-60.

9 Hamm CW, Ravkilde J, Gerhardt W, Jorgansen P, Penheim E, Ljungdahl L, et al. The prognostic value of serum troponin $T$ in unstable angina. N Engl F Med 1992;327:146-50.

10 Seino $Y$, Tonita $Y$, Talaeno $T$, Hayakawa $H$. Early identification of cardiac events with serum troponin $T$ in patients with unstable angina. Lancet 1993;342:1236-7.

11 Hobbs FDR, Kenkre JE, Carter YH, Thorpe GH. Cost and clinical effectiveness evaluation of using a C-reactive protein near patient test (NycoCard) in primary care. Fam Pract 1995;12:132.

12 Stevenson GF. The small office laboratory in the cycle of laboratory medicine: reinventing the magic black box. $¥ A M A 1985 ; 254: 2949-51$.

13 Stewart MW, Laker MF, Alberti KGM. Effects of self monitoring of triglyceride concentrations in non-insulin dependent diabetes. $B M \mathcal{1} 1993 ; 306: 493$.

14 Fitzmaurice DA, Hobbs FDR, Murray ET, Gilbert Rose PE. A randomised controlled trial comparing primary care oral anticoagulant management utilising computerised decision support (DSS) and near patient testing (NPT) with traditional management. Fam Pract 1995;12:253-4.

15 WHO Regional Office for Europe. The role of laboratory medicine in primary health care. A report from the programme on quality of care and technologies. Copenhagen: WHO, 1989.

16 Freeman GK. Desktop laboratory technology for general practice. Br f Gen Pract 1992;42;31 1-2.

\title{
Impaired glucose tolerance
}

\section{Detection and follow up should aim to reduce excess morbidity and mortality}

Impaired glucose tolerance is defined as a fasting plasma glucose concentration of less than $7.8 \mathrm{mmol} / 1$ and between $7 \cdot 8$ and $11.1 \mathrm{mmol} / 1$ two hours after a $75 \mathrm{~g}$ oral glucose load. This definition was first established in 1980 by the World Health Organisation, replacing terms such as "borderline" or "chemical" diabetes. ${ }^{1}$ It is based on long term prospective studies which conclude that individuals with lesser degrees of glucose intolerance are not at risk of microvascular complications such as retinopathy. ${ }^{2}$ The advent of health promotion clinics and screening programmes is likely to mean higher rates of detection. However, the clinical significance of impaired glucose tolerance remains unclear. ${ }^{3}$ Should people who are found to have impaired glucose tolerance be followed up, and what treatment, if any, should they receive?

Impaired glucose tolerance is common; it affects about $11 \%$ of people aged 20-74 years in the United States and $17 \%$ of those aged 40-65 years in Britain. ${ }^{45}$ The pathogenesis is controversial, particularly the question of whether it is insulin resistance or insulin deficiency that predominates. (This may have implications for treatment since potential therapeutic agents have quite different mechanisms of action: sulphonylureas act by increasing insulin secretion, with some reports that they restore the early insulin release from pancreatic beta cells (the first phase insulin response); whereas newer agents such as the thiazolidinedione derivatives act by reducing insulin resistance.) Some studies have shown that people with impaired glucose tolerance have evidence of insulin resistance and hyperinsulinaemia. ${ }^{6}$ However, the first phase insulin response, thought to be a critical factor in determining overall glucose tolerance, has been shown to be reduced in these people, showing that the development of impaired glucose tolerance requires both insulin resistance and impaired insulin secretion. ${ }^{78}$ O'Rahilly et al showed that the normal pattern of pulsatile insulin secretion was lost in people with impaired glucose tolerance, and there may be qualitative as well as quantitative abnormalities of insulin secretion. ${ }^{9}$

People with impaired glucose tolerance have increased mortality from cardiovascular disease: the Whitehall study found that impaired glucose tolerance doubled the risk of death from coronary artery disease among middle aged male civil servants. ${ }^{10}$ This has traditionally been ascribed to factors associated with glucose intolerance that exacerbate the atherogenic process. However, it has not been possible to explain the association between impaired glucose tolerance and cardiovascular disease by generally accepted risk factors such as diastolic hypertension, hypercholesterolaemia, or cigarette smoking; and epidemiological studies have found no association between coronary artery disease and either blood glucose concentration or duration of diabetes. ${ }^{11}{ }^{12}$ Reports that lipoprotein(a) concentrations may be increased in people with impaired glucose tolerance have limited implications for 
treatment as there are no effective agents which significantly lower lipoprotein(a). ${ }^{13}$

The natural history of impaired glucose tolerance is well documented. In a 10 year follow up study, $15 \%$ of people with impaired glucose tolerance went on to develop non-insulin dependent diabetes, $22 \%$ remained glucose intolerant, and the majority (53\%) improved. ${ }^{14}$ Increasing age was an independent risk factor for developing diabetes, although other studies have found no such effect. ${ }^{15}$ Patients with transient impaired glucose tolerance tend to revert to normal within about six months, but they remain at increased long term risk of developing non-insulin dependent diabetes. ${ }^{16}{ }^{17}$ By the time they develop diabetes, $50 \%$ will already have established complications, $16 \%$ coronary artery disease, and 30\% retinopathy. ${ }^{18}$ This suggests that intervening at an earlier stage may be beneficial. But who might benefit from intervention, and what form should the intervention take?

There are no clear biochemical markers that predict those at particular risk of progression to diabetes. In prospective studies the only consistent predictor was the initial degree of hyperglycaemia. ${ }^{141519}$ Subjects who did not go on to develop diabetes had mean fasting plasma glucose levels of $5 \cdot 2 \mathrm{mmol} / 1$, compared to mean levels of $5.7 \mathrm{mmol} / \mathrm{l}$ in those who developed diabetes. ${ }^{15}$ Drug and dietary interventions have shown conflicting results regarding the progression of impaired glucose tolerance to non-insulin dependent diabetes. More recently, diet and exercise intervention programmes have shown some encouraging results and reduced the risk of developing non-insulin dependent diabetes in patients with impaired glucose tolerance. A formal programme aiming to increase levels of physical activity in people with impaired glucose tolerance gave a relative risk of developing diabetes of 0.37 compared with controls. ${ }^{15}$

While many aspects of impaired glucose tolerance remain unclear, what is clear is that people with impaired glucose tolerance are susceptible to deteriorating glucose tolerance and macrovascular disease. Evidence suggests that once these patients are identified they should be advised about modifying their lifestyle, in particular to stop smoking, to lose weight if they are obese, and to maintain a reasonable level of physical fitness. They should be screened and treated for cardiovascular risk factors, particularly for hypertension and adverse fasting lipid profile (including high density lipoprotein and low density lipoprotein cholesterol and triglyceride estimation). Annual follow up examinations should include a test of fasting plasma glucose concentration, since this is the best predictor of risk of developing diabetes. A suggested cut off, based on prospective studies, ${ }^{14} 1920$ is $5 \cdot 5 \mathrm{mmol} / 1$, and indeed this figure is the entry criterion for two ongoing studies (the fasting hyperglycaemia study and the early diabetes intervention trial) which aim to examine the effects of dietary intervention, exercise, and treatment with agents such as sulphonylureas and acarbose.

Department of Diabetes,

MELANIE J DAVIES

Leicester Royal Infirmary,

Leicester LE1 5WW

Consultant physician

University of Witwatersrand,

Parktown,

Johannesburg 2193,

Republic of South Africa

1 World Health Organisation Expert Committee on Diabetes Mellitus. Second Report. Tech Rep Ser 1980 ; No 646.

Jarrett RJ, Keen H. Hyperglycaemia and diabetes mellitus. Lancet 1976;ii:1009-12.

3 Yudkin JS, Alberti KGMM, Mclarty DG, Swai ABM. Impaired glucose tolerance: is it a risk factor for diabetes or a diagnostic ragbag? $B M F$ 1990;301:397-401.

4 Harris M. Impaired glucose tolerance in the US population. Diabetes Care 1989;12:464-74.

5 Brown DC, Byrne CD, Clark PMS, Cox L, Day NE, Hales CN, et al. Height and glucose tolerance in adult subjects. Diabetologia 1991;34:531-3.

Reaven GM. Role of insulin resistance in human disease. Diabetes 1988;37:1595-607.

7 Eriksson J, Franssila-Kallunki A, Ekstrand A, Saloranto C, Widen E, Schalin C, et al. Early metabolic defects in persons at increased risk for non-insulin-dependent diabetes mellitus. $N$ Engl F Med 1989;321:337-43.

8 Davies MJ, Rayman G, Grenfell A, Gray IP, Day JL, Hales CN. Loss of the first phase insulin response to intravenous glucose in subjects with persistent impaired glucose tolerance Diabetic Med 1994;11:432-6.

9 O'Rahilly S, Turner RC, Matthews DR. Impaired pulsatile secretion of insulin in relatives of patients with non-insulin-dependent diabetes. $N$ Engl f $M e d$ 1988;318:1225-30.

10 Fuller JH, Shipley MJ, Rose G, Jarrett RJ, Keen H. Coronary-heart disease risk and impaired glucose tolerance: the Whitehall study. Lancet 1980:i:1373-6.

11 Jarrett RJ, Shipley MJ. Type 2 (non-insulin-dependent) diabetes mellitus and cardiovascular disease: putative association via common antecedents; further evidence from the Whitehall disease: putative association via
study. Diabetologia 1988;31:737-41.

12 West KM, Ahuja MMS, Bennert PH, Czczyk A, Mateo de Acosta O, Fuller JH, et al. The role of circulating glucose and triglyceride concentrations and their interactions with other "risk factors" as determinants of arterial disease in nine diabetic populations samples from the WHO multinational study. Diabetes Care 1983;6:361-9.

13 Davies MJ, Rayman G, Day JL. Increased cardiovascular mortality in subjects with impaired glucose tolerance link with serum lipoprotein(a). $B M F$ 1992;304:1610-1.

14 Keen H, Jarrett RJ, McCartney P. The ten-year follow up of the Bedford survey (1962-1972): glucose tolerance and diabetes. Diabetologia 1982;22:73-8.

15 Kadowaki T, Miyake Y, Hagura R, Akanuma Y, Kajinuma H, Kuzuya N, et al. Risk factors for worsening to diabetes in subjects with impaired glucose tolerance. Diabetologia 1984;26:44-9.

16 Davies MJ, Rayman G, Gray IP, Day JL, Hales CN. Insulin deficiency and increased plasma concentration of intact and 32/33 split proinsulin in subjects with impaired glucose tolerance. Diabetic Med1993;10:313-20.

17 Saad MF, Knowler WC, Pettitt DJ, Nelson RJ, Bennett PH. Transient impaired glucose tolerance in Pima Indians: is it important? $B M F$ 1988;297:1438-40.

18 United Kingdom Prospective Diabetes Study Group. UK prospective diabetes study (UKPDS) XII. Differences between Asian, Afro-Caribbean and White Caucasian Type 2 diabetic patients at diagnosis of diabetes. Diabetic Med 1994;11:670-7.

19 Jarrett RJ, Keen H, Fuller JH, McCartney M. Worsening to diabetes in men with impaired glucose tolerance. Diabetologia 1979;16:25-30.

20 Eriksson KF, Lindgarde F. Prevention of type 2 (non-insulin-dependent) diabetes mellitus by diet and physical exercise: the 6-year Malmo feasibility study. Diabetologia 1991;24:891-8.

\section{Chronic coronary artery disease: drugs, angioplasty, or surgery?}

\section{Tailor the treatment to the patient}

The cardiovascular community has been studying the effectiveness of percutaneous transluminal coronary angioplasty for about 15 years and coronary artery bypass graft surgery for about 25; yet important questions remain about the relative roles of these two revascularisation procedures in patients with chronic coronary artery disease. A recent metaanalysis comparing angioplasty with bypass surgery ${ }^{1}$ is most appropriately interpreted in the context of previous trials comparing angioplasty or bypass surgery with medical treatment.

An overview of randomised trials published in 1994 included data on about 2500 patients; it found that bypass surgery resulted in a highly significant overall reduction in mortality compared to initial medical treatment in patients with chronic coronary artery disease. ${ }^{2}$ This difference in mortality was clearly evident only after four to five years of follow up and was confined to patients at high and moderate risk of death (those with five year mortality during medical treatment ranging from $25 \%$ to about $12 \%$, in whom the risk reduction with bypass surgery was $50 \%$ and about $37 \%$, respectively.) Patients at low risk of death (those with five year mortality rates of about $5 \%$ ) were not likely to live longer after bypass surgery.

Two trials have compared medical treatment with angioplasty in patients with single vessel disease.$^{34}$ Neither trial was 